CAHIERS DE

NARRATOLOGIE

\section{Cahiers de Narratologie}

Analyse et théorie narratives

26 | 2014

Nouvelles frontières du récit. Au-delà de l'opposition entre factuel et fictionnel

\title{
Compte rendu : «Armand Simonnot, bûcheron du Morvan. Communisme, Résistance »
}

Boursier, Jean-Yves, « Armand Simonnot, bûcheron du Morvan.

Communisme, Résistance, Maquis », Paris, L'Harmattan, 2013, collection Terrains : récits et fictions

\section{Marc Marti}

\section{CpenEdition}

\section{Journals}

Electronic version

URL: http://journals.openedition.org/narratologie/6841

DOI: 10.4000/narratologie.6841

ISSN: $1765-307 X$

Publisher

LIRCES

Electronic reference

Marc Marti, «Compte rendu : "Armand Simonnot, bûcheron du Morvan. Communisme,

Résistance » », Cahiers de Narratologie [Online], 26 | 2014, Online since 11 September 2014, connection on 20 April 2019. URL : http://journals.openedition.org/narratologie/6841 ; DOI : 10.4000/ narratologie. 6841

This text was automatically generated on 20 April 2019.

Article L.111-1 du Code de la propriété intellectuelle. 


\section{Compte rendu : "Armand Simonnot, bûcheron du Morvan. Communisme, Résistance "}

Boursier, Jean-Yves, « Armand Simonnot, bûcheron du Morvan. Communisme, Résistance, Maquis », Paris, L'Harmattan, 2013, collection Terrains : récits et fictions

Marc Marti

1 Cet ouvrage est le résultat de nombreux entretiens menés par Jean-Yves Boursier dans le Morvan, avec Armand Simonnot, ancien bûcheron, charpentier, militant pacifiste puis communiste, premier Franc Tireur et Partisan (FTP) devenu après la guerre le garde du corps de Charles Tillon (ancien chef des FTP) qu'il a ensuite accompagné dans l'exil lors du procès stalinien qui lui fut intenté en 1952.

2 C'est un travail de micro-histoire très documenté, par l'abondance des sources écrites et la richesse des entretiens menés. Il rend compte des valeurs qui animaient quelques acteurs individuels, dont Armand Simonnot, à travers leur action, leur prise de position et leur comportement courageux lors d'une période troublée.

3 Au-delà des acteurs eux-mêmes, l'analyse et le récit permettent de saisir le fonctionnement détaillé des sociétés villageoises et de leur évolution socio-politique pendant le « court XXe siècle » que constitue la période traitée. Il embrasse l'histoire de France par l'analyse minutieuse de l'histoire d'un de ses territoires et des composantes sociales, économiques et politiques qui le constituaient.

4 Il éclaire aussi sous un jour nouveau l'histoire du PCF et surtout de ses militants, considérés ici dans toute leur singularité, dans leur rapport compliqué, parfois conflictuel avec la (les) ligne(s) politique(s) successive(s) du Parti et leurs propres actions individuelles. Du pacte germano-soviétique aux tentatives de légalisation sous Vichy, puis à l'organisation des FTP, pour terminer par « le Parti des 75000 fusillés », la recherche 
recoupe les entretiens individuels avec les documents d'archives et les ouvrages des historiens du Parti.

Si le propos général peut relever de l'histoire, la méthode de travail retiendra l'attention de ceux qui s'intéressent au récit et aux méandres qu'il emprunte dans les vastes plaines de la mémoire et de la subjectivité. Les premières pages de l'ouvrage sont en effet une très efficace mise au point sur ce que doit être l'enquête et sur la façon dont l'ethnologue doit ensuite la considérer.

6 Dans le cas présent, comme le rappelle l'auteur, c'est d'abord la parole d'un témoin singulier qui l'intéressait, parce qu'elle constituait «l'exercice de la mémoire vivante». Ces entretiens sont fondamentaux pour l'ethnologue, surtout à partir du moment où, comme Jean-Yves Boursier, il sait reconnaître que cette parole « évolue dans le temps et selon les temps ». Sur le terrain, il a pu ainsi " constater des variations dans les "dires" de certains interlocuteurs qui ne peuvent être de la bonne ou de la mauvaise foi. Cela tient pour une part à la formulation de la question, mais surtout au cadre politique de la mémoire. C'est particulièrement vrai pour des anciens militants du PCF qui plaquent parfois abstraitement le discours convenu du "Parti" sur leur expérience originale, afin que leur récit s'intègre à celui du "Parti”. Ce n'était pas le cas d'Armand Simonnot ». Cette analyse de Jean-Yves Boursier, ici pour le cas de la Résistance et du récit postérieur qu'en a fait le PCF, souligne les écarts entre la mémoire individuelle, son expression par la parole et la mémoire consacrée, rigide, très souvent écrite, des institutions, dont l'objectif ultime est d'offrir une lecture consensuelle, valorisante, mais sans nuance de l'Histoire.

7 Dans ce cadre, la « construction subjective » que constitue la parole et sa mise en récit «se différencie des textes prétendant exprimer une vérité sur une question dès l'instant où ils seraient élaborés à partir d'archives [...]». Cependant, «il existe des dynamiques internes qui ne sont pas intelligibles par l'archive, d'autant plus qu'elles se sont déployées au sein des groupes dans des rapports de face à face, directs, marqués par l'oralité mais aussi le silence ».

8 L'ouvrage, qui se nourrit des entretiens et les met en récit, les resitue aussi par rapport à d'autres récits et en approfondit certains en recourant à l'archive. L'Histoire officielle se trouve ainsi déconstruite. L'auteur met en relief les contradictions, les simplifications, les falsifications et les silences sur lesquels elle s'est constituée. Le réel de la Résistance, qui occupe la majeure partie du travail, est rendu dans sa complexité et délivré des très nombreuses mythifications qui ont longtemps pesé sur sa représentation.

Il ne s'agit pas cependant d'opposer des récits individuels à un "grand récit» institutionnalisé (autant celui du PCF que de la France libérée). C'est plutôt un croisement de récits, multiforme et polyphonique, qui permet de comprendre la complexité de l'Histoire, la participation et le rôle des individus dans leur temps présent, le rapport complexe et parfois contradictoire de la mémoire individuelle avec la mémoire et l'histoire collective. 


\section{AUTHOR}

\section{MARC MARTI}

Université Nice Sophia Antipolis, LIRCES, EA 3159, 06200 Nice, France 